\title{
THÀNH LẬP NHANH BẢN ĐỒ LŨ BẰNG CHỈ SỐ LŨ KHÁC BIẸT CHUẨN HÓA NDFI VÀ CHİ SỐ KHÁC BIẸT LŨ TRONG VÙNG THỰC VẬT THẤP NDFVI SỬ DỤNG LỢI THẾ CỦA HỆ THỐNG VIETNAM DATA CUBE
}

\author{
LÊ TH!̣ THU HẰNG ${ }^{(1)}$, PHẠM MINH HẢI ${ }^{(2)}$, \\ VŨ ANH TUÂN ${ }^{(1)}$, NGUYỄN HỒNG QUẢNG ${ }^{(1)}$ \\ (l) Trung tâm Vũ tru Việt Nam, Việt Hàn lâm Khoa học và Công nghệ Việt Nam \\ ${ }^{(2)}$ Viện Khoa học Đo đạc và Bản đồ
}

\section{Tóm tắt:}

Trong bối cảnh biến đổi khi hậu, việc có được một bản đồ lũ kịp thời và chính xác ngay khi thiên tai là thực sự cần thiết trong việc lập kế hoạch quản lý khẩn cấp nhằm giảm thiểu rủi ro thiên tai môt cách hiệu quả. Nghiên cưu áp dụng một phuơng pháp lập bản đồ lũ lụt nhanh dựa trên hai chỉ số khác biệt lũ chuẩn hóa (NDFI - Normalized Difference Flood Index) và chỉ số khác biệt lũ trong vùng thục vật thấp (NDFVI - Normalized Difference Flood in short Vegetation Index) tù̀ chuỗi dũ liệu của ảnh Radar khẩu độ tổng hợp (SAR - Synthetic Aperture Radar) Sentinel-1. Hai chỉ số này được tính toán, trên các cảnh ảnh trước lũ và trong lúc có lũ, tù đó lập bản đồ các khu vực ngập nước lũ và các khu vực có nước ngập thảm thực vật thấp bằng phuơng pháp phân nguõng. Dũ liệu SAR băng tần C của vệ tinh Sentinel-1 được sủ dụng trong nghiên cúu này do đây là nguồn dũ liệu miễn phí và có tần suất chụp ảnh khá tốt (12 ngày). Tuy vậy, phuơng pháp cũng có thể được áp dụng cho tất cả các dũ liệu vệ tinh SAR băng $C$ khác để tăng cao tần suất quan sát, một điều rất cần thiết trong theo dõi lũ. Áp dụng phương pháp trên khu vục thư nghiệm tỉnh Đồng Tháp năm 2018 cho thấy có độ tin câyy cao và hiệu quả của phurong pháp qua việc đánh giá, so sánh với dũ liệu thực địa gồm 143 điểm. Hiện nay, toàn bộ ảnh Sentinel-1 đã được thu thập và liên tuc cập nhật trong hệ thống Vietnam Data Cube do Trung tâm Vũ trụ Việt Nam vận hành cho phép áp dụng phrơng pháp trên toàn lãnh thổ Việt Nam.

\section{Giới thiệu}

Lũ lụt, cùng với bão và trượt lở đất, là một trong những mối nguy hiểm tự nhiên phổ biến nhất tại Việt Nam. Thách thức chính trong công tác phòng chống lũ là có được thông tin kịp thời và chính xác về phạm vi ảnh hưởng, sự phát triển và khả năng lan truyền dòng chảy lũ theo thời gian.

Giám sát lũ sử dụng công nghệ vệ tinh (ảnh viễn thám hoặc lượng mưa) được nhiều nhà nghiên cứu quan tâm và đưa ra các phương pháp khác nhau, từ thành lập bản đồ lũ $[1,6,7,9]$, cảnh báo sớm $[3,2]$, theo dõi lũ $[4,8,12]$, dự báo diễn biến của lũ nhờ các mô hình $[11,5]$. Trong việc giám sát lũ, phương pháp truyền thống như khảo sát mặt đất, hay thực hiện quan sát từ máy bay gặp nhiều khó khăn vì khu vực lũ thường khó tiếp cận, thời tiết xấu dẫn tới kết quả không kịp thời và thiếu chính xác. Lợi thế của ảnh SAR trong theo dõi lũ là không phụ thuộc vào điều kiện thời tiết, khả năng theo dõi thường xuyên hơn do có thể quan sát bề mặt Trái đất vào ban đêm. Dữ liệu SAR có đặc điểm phản xạ gần như hoàn toàn trên bề mặt nước nên tín hiệu tán xạ phản hồi mà sensor thu nhận được gần như bằng "không”[7]. Đây là đặc điểm quan trọng để nhận biết bề mặt nước trên ảnh SAR trong các nghiên cứu về lũ lụt. Tuy vậy, thông thường, với các khu vực lũ không phải lúc nào cũng gặp mặt nước

Ngày nhận bài: 02/06/2020, ngày chuyển phản biện: 05/06/2020, ngày chấp nhận phản biện: 10/06/2020, ngày chấp nhận đăng: 12/06/2020 
trống nên tán xạ phản hồi của khu vực lũ khá phức tạp, nhất là khi có sự tham gia của thực vật hoặc các công trình nhân tạo. Phản xạ góc trên ảnh SAR khi đó có thể tạo nên những vùng tán xạ khá mạnh và gây nhiễu khá lớn. Chính vì vậy, sử dụng ảnh SAR cho theo dõi lũ đang được phát triển mạnh mẽ trong những năm gần đây.

Trên thế giới, các nghiên cứu sử dụng dữ liệu vệ tinh SAR trong giám sát lũ lụt thường tập trung vào phân tích đặc điểm tán xạ phản hồi trên ảnh SAR của các vùng ngập kết hợp với các nguồn thông tin khác từ ảnh quang học hoặc từ thực địa. Rahman và Thakur (2017) sử dụng dũ liệu vệ tinh SAR kết hợp với GIS để phát hiện, giám sát, thành lập và phân tích bản đồ lũ lụt cho khu vực Kendrapara, Ân Độ [8]. Nghiên cé cứu đã sử dụng một chuỗi các bức ảnh RADARSAT1 SAR (chế độ chụp ScanSAR wide) kết hợp dũ liệu vệ tinh đa phổ của Ân Độ IRS 1C LISS III và số liệu thực địa để trích xuất dữ liệu nước bề mặt ở thời điểm trước lũ; Năm 2015, Schlaffer và các cộng sự đề xuất phương pháp phân tích hài hòa (Harmonic analysis) trong xác định ngưỡng trong nghiên cứu phát hiện lũ từ dữ liệu SAR đa thời gian để xem xét sự thay đổi của lũ tại trận lũ lớn xảy ra vào mùa hè năm 2007 ở khu vực sông Severn (Anh)[9]; Tập trung vào việc tìm hiểu và đánh giá sai số thành lập bản đồ lũ từ ảnh SAR, Giustarini và các cộng sự (2015) đã tiến hành đánh giá các nguồn gây ra sai số thông qua hai đợt lũ xảy ra vào tháng 7/2007 ở khu vực Tewkesbury nước Anh [10]. Nghiên cứu này sử dụng hai bộ ảnh từ hai cảm biến SAR khác nhau, bao gồm: hai ảnh ENVISAT ASAR với dải quét rộng và hai ảnh StripMap TerraSAR-X. Ở Việt Nam cũng có một số nghiên cứu ứng dụng dữ liệu SAR trong nghiên cứu lũ lụt điển hình như [11], [12], [13], [4-6]. Trong đó, nghiên cứu "ứng dụng viễn thám và công nghệ GIS nghiên cứu diễn biến lũ Đồng bằng sông Cửu Long giai đoạn 1993-1998" của tác giả Bùi Doãn Trọng đã xây dựng được quy trình công nghệ thành lập bản đồ hiện trạng ngập lụt sử dụng kết hợp mô hình hóa và các kỹ thuật phân tích ảnh radar. Nghiên cứu kỹ thuật tổ hợp màu khá đơn giản để nhận biết các khu vực lũ.

Hầu hết các nghiên cứu, công tác thu thập thông tin về vùng lũ trên ảnh SAR đều dựa vào tính chất phản xạ hoàn toàn (trong trường hợp mặt nước "phẳng" với bước sóng radar) khi tương tác với mặt nước để xác định giá trị ngưỡng gần với giá trị không có tán xạ phản hồi. Trên thực tế Việt Nam, nhiều khu vực bị ngập lụt hoặc lũ có thực vật bao phủ, và các thực vật này không bị ngập hoàn toàn khiến cho tương tác của tia radar với khu vực ngập lụt trở nên phức tạp hơn nhiều. Vì vậy, việc nghiên cứu lũ lụt không thể chỉ dựa vào ảnh chụp khi có lũ mà cần bắt đầu từ khi chưa có lũ lụt. Do đó việc theo dõi lũ lụt bằng ảnh $\mathrm{SAR}$ thường đòi hỏi có lượng lớn ảnh đa thời gian. Việc sử dụng chuỗi ảnh đa thời gian khẳng định thêm về tính chính xác của hình ảnh trước lũ để từ đó phép tách lũ chính xác hơn. Hiện nay, với chuỗi dữ liệu ảnh SAR đủ dài, đã được thu thập và lưu trữ trên hệ thống Vietnam Data Cube của Trung tâm Vũ trụ Việt Nam, trong nghiên cứu này chúng tôi sẽ thử nghiệm để nghiên cứu, thành lập bản đồ lũ nhanh cho khu vực tỉnh Đồng Tháp, nơi có đặc điểm lũ đặc trưng cho khu vực Đồng bằng sông Cửu Long bằng chỉ số khác biệt lũ được chuẩn hóa NDFI và chỉ số khác biệt lũ trong vùng thực vật thấp NDFVI.

\section{Khu vực nghiên cứu}

Đồng Tháp là tỉnh nằm ở vùng hạ lưu sông Mê Kông, nơi sông Mê Kông chảy vào Việt Nam từ Campuchia, địa hình tương đối bằng phẳng, độ cao phổ biến 1-2 mét so với mặt biển. Đồng Tháp nằm trong vùng khí hậu nhiệt đới chia làm 2 mùa rõ rệt là mùa mưa và mùa khô. Độ ẩm trung bình năm là $82,5 \%$. Lượng mưa trung bình từ $1.170-1.520 \mathrm{~mm}$, tập trung vào mùa mưa, chiếm 90 - 95\% lượng mưa cả năm. Đồng Tháp có mạng lưới sông rạch dày đặc với hai sông chính là sông Tiền và sông Hậu.

Trong đó, sông Tiền phân chia không gian lãnh thổ tỉnh thành hai bộ phận, phần phía Bắc thuộc vùng Đồng Tháp Mười thấp trũng, phần phía Nam nằm kẹp giữa sông Tiền và sông Hậu 
được bồi đắp phù sa hàng năm. Trong bối cảnh biến đổi khí hậu hiện nay, vùng Đồng bằng sông Cửu long (ĐBSCL) nói chung và tỉnh Đồng Tháp, chế độ lũ của sông Mê Kông đã và đang có những biến động rất thất thường, và việc theo dõi thường xuyên tình hình lũ luôn là một đòi hỏi cấp thiết.

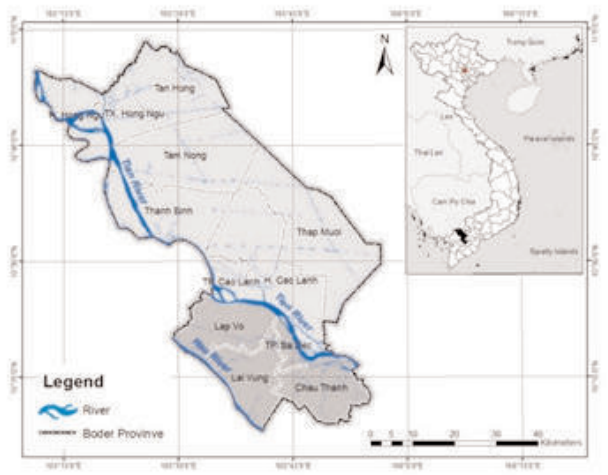

Hình 1: Khu vục nghiên cứu-Tỉnh Đồng Tháp

Đồng Tháp có đặc điểm lũ đặc trưng cho khu vực Đồng bằng sông Cửu Long (ĐBSCL). Lũ lụt diễn ra ở Đồng Tháp thuộc loại sớm, phức tạp nhất ở ĐBSCL. Đặc điểm lũ tại tỉnh Đồng Tháp chủ yếu do mưa trên lưu vực sông Mê Kông gây ra. Hàng năm, mùa lũ xảy ra đồng thời với mùa mưa, kéo dài liên tục khoảng 4-5 tháng, thường từ tháng 6 đến tháng 11. Lũ ĐBSCL thường có hai đỉnh, đỉnh đầu thường xảy ra cuối tháng 7 đến giữa tháng 8 ; đỉnh sau cuối tháng 9 đến đầu tháng 10 , mực nước đỉnh lũ cao nhất thường xuất hiện vào khoảng ngày 15/9 - 15/10. Trung bình cứ khoảng 6 - 7 năm có một năm lũ lớn (lũ có mực nước đỉnh lũ cao hơn trung bình nhiều năm)

\section{Dữ liệu sử dụng}

Để theo dõi diễn biến lũ tại khu vực nghiên cứu, 7 cảnh ảnh Sentinel-1 (băng C) được chụp trong khoảng thời gian từ tháng 7 năm 2018 đến tháng 11 năm 2018 được thu thập phục vụ phân tích lũ, trong đó có hai ảnh chụp tháng 7/2018 là trước khi có lũ. Các ảnh được sử dụng đều có phân cực VH.

Bên cạnh đó, dữ liệu thực địa được thu thập trong khoảng thời gian đầu tháng 10/2018 nhằm phục vụ đánh giá độ chính xác của phương pháp. Chi tiết của dữ liệu sử dụng trong nghiên cứu được trình bày ở bảng 1 .

\section{Phương pháp nghiên cứu}

Trong nghiên cứu này chúng tôi phát triển phương pháp lập bản đồ lũ dựa trên phân tích chuỗi ảnh đa thời gian thông qua tính toán hai chỉ số khác biệt lũ được chuẩn hóa NDFI (Normalized Difference Flood Index) và chỉ số khác biệt lũ trong vùng thực vật thấp NDFVI (Normalized Difference Flood in short Vegetation Index) theo phương pháp của Cian và cộng sự năm 2018 [14]. Sơ đồ các bước thành lập bản đồ lũ sử dụng NDFI và NDFVI được thể hiện trong Hình 2, bao gồm: tiền xử lý ảnh SAR (hiệu chỉnh bức xạ, hiệu chỉnh hình học, lọc nhiễu); tính toán chỉ số NDFI và NDFVI; chọn ngưỡng phân loại; thành lập bản đồ lũ nhanh. Chỉ số NDFI và NDFVI được tính toán trên hai bộ dữ liệu, một là những ảnh trước lũ và hai là các ảnh khi có lũ.

Trong các bước kể trên, hai bước quan trọng nhất là tính toán chỉ số NDFI và NDFVI và lựa chọn ngưỡng phân loại lũ/không lũ. Hai bước này quyết định đến độ chính xác của kết quả.

(Xem hình 2)

Bảng 1: Dũ liệu nghiên cưu

\begin{tabular}{|c|c|c|c|}
\hline STT & Dữ liệu & Ngày chụp & Trạng thái \\
\hline 1 & Sentinel 1A (VH) & $18 / 7 / 2018$ & Ảnh trước lũ \\
\hline 2 & Sentinel 1A (VH) & $30 / 7 / 2018$ & Ảnh trước lũ \\
\hline 3 & Sentinel 1A (VH) & $11 / 8 / 2018$ & Ảnh lũ \\
\hline 4 & Sentinel 1A (VH) & $16 / 9 / 2018$ & Ảnh lũ \\
\hline 5 & Sentinel 1A (VH) & $10 / 10 / 2018$ & Ảnh lũ \\
\hline 6 & Sentinel 1A (VH) & $22 / 10 / 2018$ & Ảnh lũ \\
\hline 7 & Sentinel 1A (VH) & $03 / 11 / 2018$ & Ảnh lũ \\
\hline 8 & Dữ liệu thực địa & Từ $2 / 10$ đến $11 / 10 / 2018$ & Trong lúc lũ \\
\hline
\end{tabular}




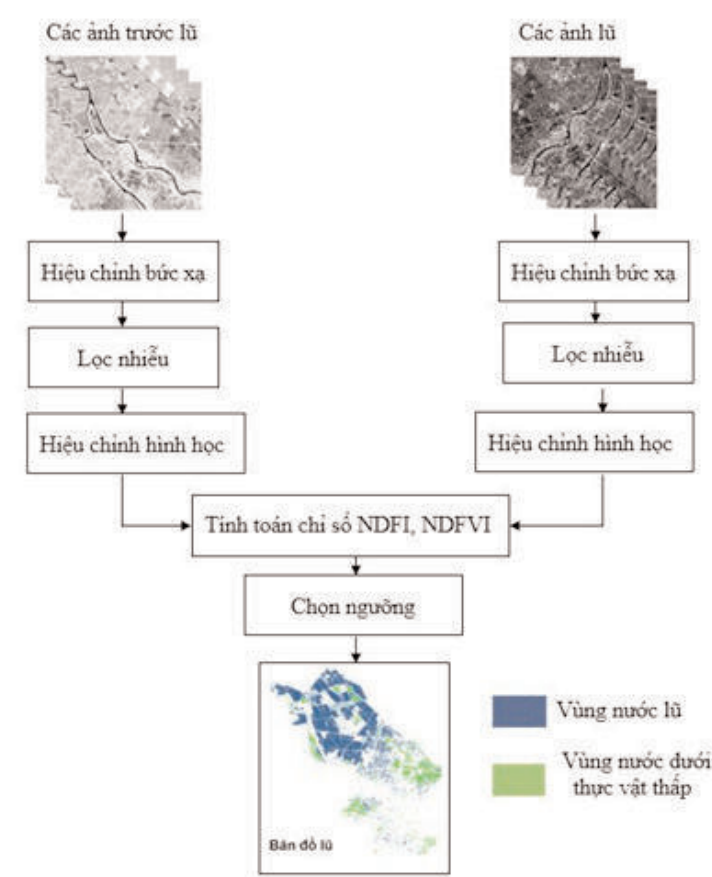

Hình 2: So đồ các bước thành lập bản đồ lũ

\subsection{Tính toán chỉ số NDFI và NDFVI}

NDFI và NDFVI được đề xuất vào năm 2018 bởi Cian và cộng sự [14]. Công thức tính NDFI như sau:

NDFI $=\frac{\text { Mean } \sigma 0(\text { reference })-\text { Min } \sigma 0(\text { "reference+flood" })}{\text { Mean } \sigma 0(\text { reference })+\text { Min } \sigma 0(\text { "reference+flood" })}$

Trong đó:

- Mean $\sigma^{0}$ ("reference"): là giá trị pixel trung bình của các ảnh trước lũ, tính theo $\sigma^{0}$

- Min $\sigma^{0}$ ("reference+flood"): là giá trị pixel nhỏ nhất của các ảnh gồm trước lũ và trong lũ, tính theo $\sigma^{0}$

NDFI cho phép dễ dàng phân loại được vùng lũ. Giá trị trung bình của từng pixel trong các ảnh trước lũ thể hiện trạng thái, giá trị trung bình của bề mặt đất. Chẳng hạn như các mặt nước cố định thể hiện giá trị trung bình thấp, các bề mặt nhẵn có giá trị trung bình tán xạ gần như bằng 0 , còn các bền mặt gồ ghề (khu vực đô thị, rừng..) có giá trị lớn hơn. Còn giá trị nhỏ nhất của mỗi pixel trong các ảnh bao gồm cả trước lũ và trong lũ được sử dụng để ghi lại cụ thể sự không liên tục trong chuỗi thời gian phân tích, nghĩa là những pixel đó trong quá trình tán xạ ngược rất thấp. Sự khác biệt giữa giá trị trung bình và giá trị nhỏ nhất đó làm nổi bật những điểm không liên tục, đó là khu vực ngập lụt. Chỉ số NDFI cho giá trị từ 0 đến 1 .

Tất cả các pixel có giá trị không thay đổi trong ảnh chỉ số có giá trị gần bằng 0 có thể dễ dàng nhận được như các vùng nước mặt cố định như sông, hồ... hay các pixel không có nước với tán xạ thấp như đường, đất khô và đường nhựa mịn. Để phát hiện được sự ngập nước trong thảm thực vật thấp, chỉ số NDFVI [14] được tính toán, đưa ra nhằm mục đích làm nổi bật sự gia tăng của tán xạ ngược xảy ra trong những trường hợp đó. Chỉ số tính toán trên cơ sở sử dụng thống kê số liệu của các ảnh trước lũ và trong lũ:

$$
\text { NDFVI }=\frac{\text { Max } \sigma 0(\text { reference }+ \text { flood })-\text { Mean } \sigma 0(\text { reference })}{\text { Max } \sigma 0(\text { reference }+ \text { flood })+\text { Mean } \sigma 0(\text { reference })}
$$

Trong đó:

- Mean $\sigma^{0}$ ("reference") ): là giá trị pixel trung bình của các ảnh trước lũ, tính theo $\sigma^{0}$

- Max $\sigma^{0}$ ("reference+flood"): là giá trị pixel lớn nhất của các ảnh gồm trước lũ và trong lũ, tính theo $\sigma^{0}$

Trong công thức (2) giá trị lớn nhất của các pixel được tính nhằm mục đích làm nổi bật sự gián đoạn trong chuỗi thời gian gây ra bởi nước nông trong thảm thực vật thấp. Sự thay đổi với giá trị trung bình làm nổi bật những pixel có mức tăng mạnh trong tán xạ ngược của chúng.

\subsection{Chọn ngương}

Lựa chọn ngưỡng sao cho phù hợp luôn là một thách thức trong thành lập bản đồ lũ. Ngưỡng không phù hợp sẽ dẫn tới sai số trong bản đồ kết quả. Nghiên cứu của Long và cộng sự (2014) đã tìm ngưỡng từ phân tích biểu đồ phân bố giá trị khác biệt của ảnh, tức là ảnh trước lũ trừ ảnh lũ. Ngưỡng là giá trị trung bình của toàn bộ giá trị ảnh thay đổi trừ $\mathrm{k}$ lần độ lệch chuẩn 
[15] được tính theo công thức (3).

$\mathrm{Th}=$ mean(NDFIflood) $-\mathrm{k}^{*} \operatorname{std}($ NDFIflood)

Giá trị $\mathrm{k}$ sẽ tương đối cố định trên cùng một khu vực vì được tính toán theo các chỉ số chuẩn hóa nên không còn phụ thuộc nhiều vào cảnh ảnh. Việc xác định giá trị $\mathrm{k}$ có thể được tiến hành thông qua phân tích định lượng bằng mắt thường hoặc tốt hơn là sử dụng các thông tin thực địa làm mẫu. Trong khu vực nghiên cứu, sau khi phân tích tính được giá trị $\mathrm{k}=1,5$ tương ứng với ngưỡng là 0,7 cho NDFI. Trên thực tế, các pixel có giá trị NDFI ở gần ngưỡng cũng có thể được tìm thấy trong đất khô, bóng hoặc các bề mặt nhẵn khác. Giảm ngưỡng sẽ dẫn đến nhiều chiết tách sai.

Với các khu vực có thực vật thấp, cách tiếp cận tương tự đã được áp dụng cho NDFVI theo công thức (4).

Thv $=$ mean (NDFVIflood veg) $+\mathrm{kv} * \mathrm{std}$ (NDFVIfloodveg)

Trong khu vực nghiên cứu, phân tích cũng cho giá trị $\mathrm{k}=1,5$, tương ứng với ngưỡng là 0,3 .

\section{Kết quả nghiên cứu}

\subsection{Bản đồ chỉ số NDFI, NDFVI}

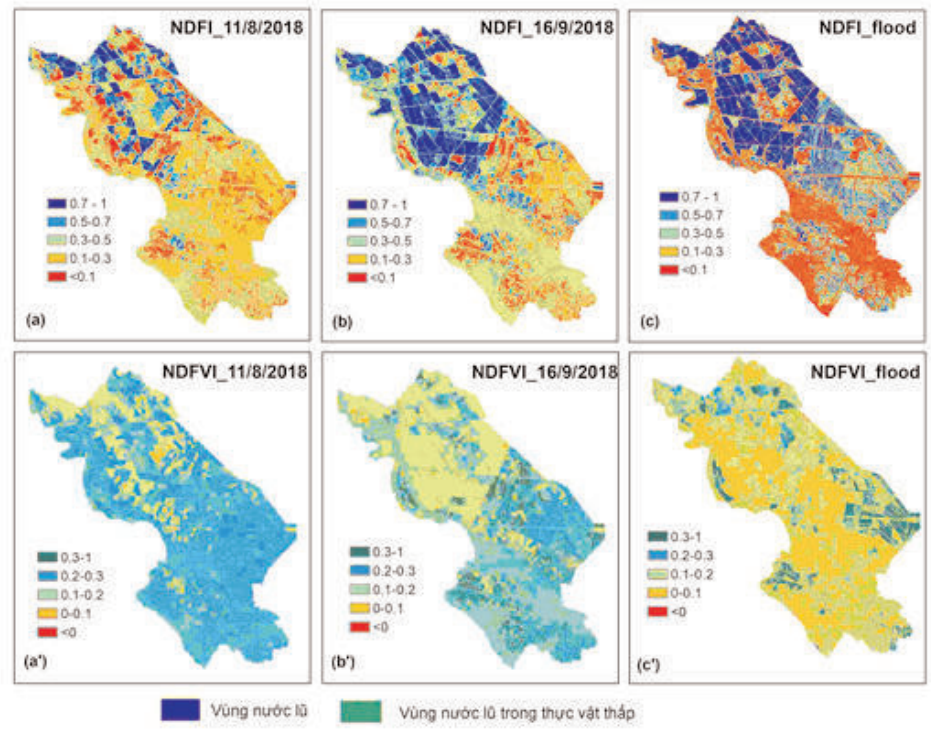

Hình 3: (a) (b) (a’) (b') là các ảnh chỉ số được tính tù các cảnh trước lũ và ảnh ngày 11/8 và 16/9/2018; (c) (c') là các ảnh chỉ số được tính tù̀ các ảnh trước lũ và các ảnh trong lũ 
ảnh trước lũ luôn lớn hơn giá trị min của các ảnh lũ. Do đó, chúng tôi loại trừ các giá trị đó trong phân tích của chúng tôi.

Khu vực phía trên đường chéo được chia làm hai với ngưỡng $(\mathrm{NDFI}=0,7)$ : diện tích (2) tương ứng với các điểm được chọn là ngập và diện tích (3) đối với các điểm không bị ngập. Giá trị NDFI gần bằng 0 thường là các vùng nước cố định (sông, hồ , ao...) và các đối tượng có đặc điểm ổn định như khu vực đô thị, đường giao thông, đường nhựa... vì chúng có giá trị tán xạ rất thấp.

Các giá trị của $\sigma^{0}$ mean từ 0 đến 0,03 cho thấy ngưỡng được áp dụng trên NDFI bao gồm một phần của khu vực này trong bản đồ ngập lụt (bên trái của ngưỡng ngưỡng màu xanh, tức là đối với các giá trị NDFI>0,7). Khu vực này có thể được chia thành hai khu vực khác: trong đó giá trị trung bình $\sigma^{0}$ mean nhỏ hơn 0,01 (giá trị chỉ đại diện cho pixel nước) và khu vực với $\sigma^{0}$ mean> 0,01 (nước có độ tán xạ lớn hơn và đất trống khô). Khu vực $<0.01$ thường liên quan đến các vùng nước vĩnh viễn được đưa vào bản đồ lũ lụt. Diện tích 0.01-0.03 chủ yếu đại diện cho đất trống khô làm giảm tán xạ ngược của chúng trong trận lụt và do đó, việc đưa chúng vào bản đồ lũ là chính xác. Còn $\sigma^{0} \min =0,01$ thể hiện tán xạ ngược tối đa của các pixel nước trong các ảnh bao gồm cả ảnh trước và sau lũ. Các vùng có $\sigma^{0} \min <0.01$ chính các pixel bị ngập mà trước không phải là nước (vì tán xạ ngược trung bình cao, $\sigma^{0}$ mean $\left.>0,03\right)$ làm giảm mạnh tán xạ ngược của chúng trong lũ lụt $\left(\sigma^{0} \min <0,03\right)$

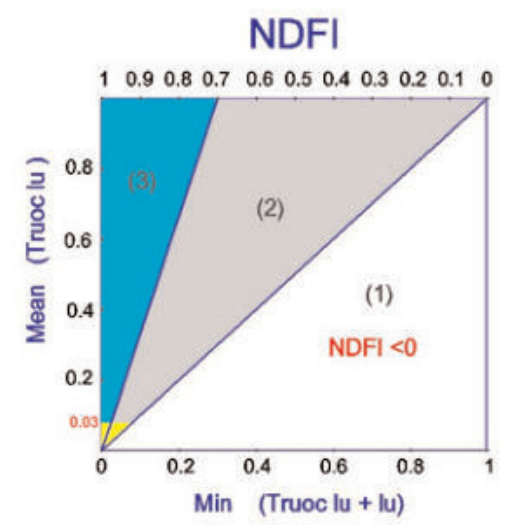

Hình 4: Phân tích chỉ số NDFI

\subsection{Bản đồ lũ}

Với giá trị ngưỡng phân tích, tính toán và lựa chọn ở mục 4.2, tiến hành tách vùng nước lũ, thành lập bản đồ lũ năm 2018. Kết quả nghiên cứu cho thấy diễn biến của lũ năm 2018 lên dần từ đầu mùa cho đến đỉnh lũ. Hình $5 \mathrm{a}^{\prime}$ thể hiện nước lũ bắt đầu lên, chỉ có một số ít vùng thấp ở huyện Hồng Ngự, Tam Nông, Thanh Bình bị ngập không đáng kể. Đến giữa tháng 9 (Hình $5 b$ ) lũ bắt đầu lên cao, ngập hầu hết gần như hoàn toàn một số huyện như Hồng Ngự, Tân Hồng, Tam Nông, Thanh Bình. Vào thời điểm đỉnh lũ (Hình $5 \mathrm{c}$ ) giữa tháng 10 thì ngập hầu hết trên toàn tỉnh. Diễn biến lũ từ kết quả này hoàn toàn phù hợp với tình hình thực tế lũ diễn ra tại mùa lũ tỉnh Đồng Tháp năm 2018 [16]. (Xem hình 5)

\section{3. Đánh giá độ chính xác}

Để đánh giá độ chính xác tiến hành so sánh bản đồ thành lập với dữ liệu thực địa cùng thời điểm $(2 / 10$ đến 11/10)

Các điểm đo thực địa được tiến hành điều tra từ ngày $2 / 10$ đến $11 / 10 / 2018$ với tổng số điểm là 143 điểm quan sát. Tại mỗi điểm quan sát quan sát chi tiết theo 4 hướng Bắc-Đông Bắc; ĐôngĐông Nam; Nam-Tây Nam và Tây-Tây Bắc (Hình 6), hiện trạng lũ tại thời điểm điều tra được ghi nhận lại trên bản đồ.

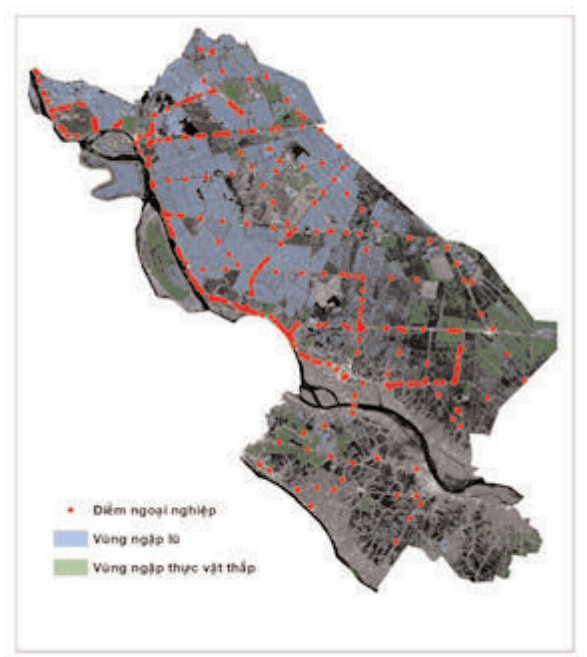

Hình 6: So đồ điểm điều tra thực địa thời điểm tù̀ 2/10 đến 11/10/2018 

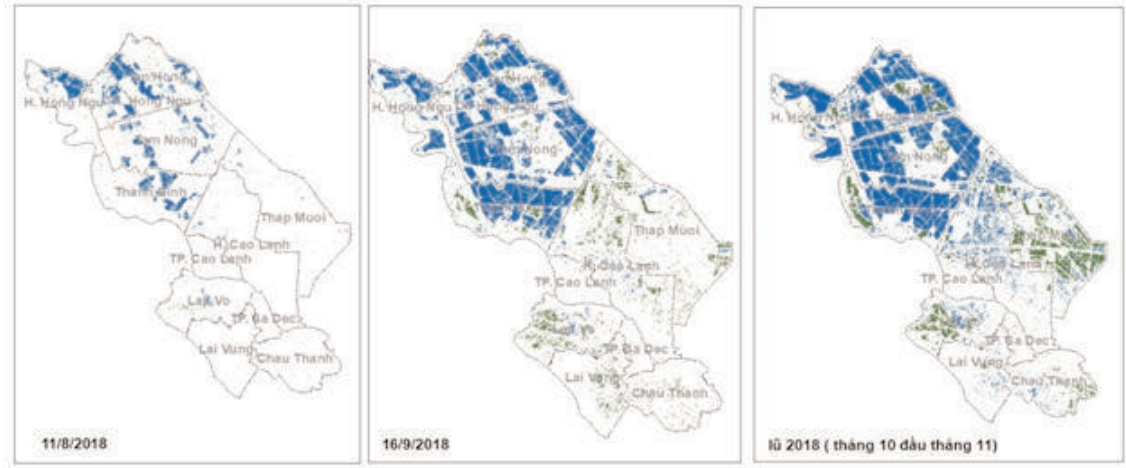

Vùng nước la

Vùng nước lu trong thục vật tháp

Hình 5: Bản đồ diễn biến lũ năm 2018

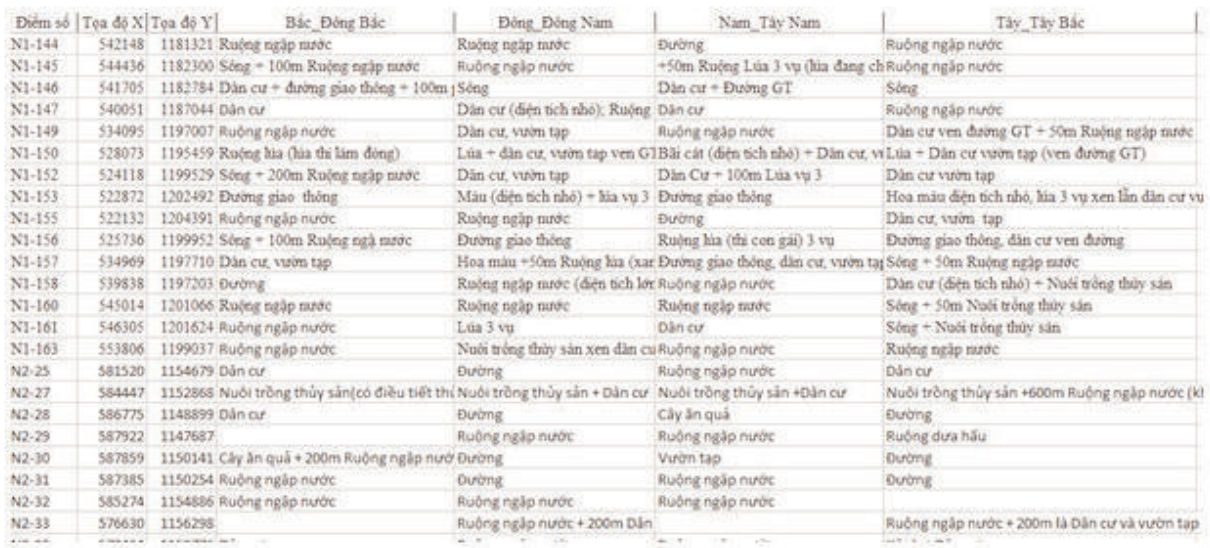

Hình 7: Kết quả điều tra thực địa

Bảng 2: So sánh kết quả ngập lũ giũa số liệu thực địa và ảnh vệ tinh

\begin{tabular}{|c|l|c|c|c|c|}
\hline STT & \multicolumn{1}{|c|}{ Tên huyện } & $\begin{array}{c}\text { Số điểm } \\
\text { điều tra } \\
\text { thực địa }\end{array}$ & $\begin{array}{c}\text { Tổng số } \\
\text { điểm * } \\
\text { hướng }\end{array}$ & $\begin{array}{c}\text { Tỉ lệ các } \\
\text { điểm giống } \\
\text { nhau }\end{array}$ & $\begin{array}{c}\text { Giống nhau } \\
(\%)\end{array}$ \\
\hline 1 & Huyện Châu Thành & 0 & 0 & & \\
\hline 2 & Huyện Cao Lãnh & 34 & 136 & $116 / 136$ & 85 \\
\hline 3 & Huyện Lai Vung & 6 & 24 & $22 / 24$ & 92 \\
\hline 4 & Huyện Lập Võ & 5 & 20 & $20 / 20$ & 100 \\
\hline 5 & Huyện Tam Nông & 34 & 136 & $128 / 136$ & 94 \\
\hline 6 & Huyện Tam Hồng & 21 & 84 & $74 / 84$ & 88 \\
\hline 7 & Huyện Thanh Bình & 13 & 52 & $50 / 52$ & 96 \\
\hline 8 & Huyện Tháp Mười & 19 & 76 & $72 / 76$ & 94 \\
\hline 9 & Thị Xã Hồng Ngự & 5 & 20 & $16 / 20$ & 80 \\
\hline 10 & Huyện Hồng Ngự & 6 & 24 & $21 / 24$ & 88 \\
\hline
\end{tabular}


Tiến hành so sánh kết quả vùng ngập lũ từ ảnh vệ tính ở bước trên với dữ liệu thực địa. Kết quả so sánh được thể hiện trong Bảng 2. (Xem hình 7, bảng 2)

Kết quả này cho thấy sự phù hợp cao giữa kết quả thành lập bản đồ lũ từ ảnh vệ tinh so với thực tế.

\section{Kết luận}

Phương pháp nghiên cứu đã thành lập nhanh được bản đồ lũ lụt dựa trên phân tích chuỗi ảnh đa thời gian có sẵn trên hệ thống dữ liệu Vietnam Data Cube của Trung tâm Vũ trụ Việt Nam. Mục đích của nghiên cứu là khai thác, sử dụng dữ liệu từ hệ thống dữ liệu lớn này. Hai chỉ số được đề xuất để lập bản đồ các khu vực bị ngập lụt là: chỉ số khác biệt lũ được chuẩn hóa NDFI và chỉ số khác biệt lũ trong vùng thực vật thấp NDFVI cho thấy một số những ưu việt đặc biệt là khả năng tách lũ dưới khu vực thực có thực vật thấp. Nghiên cứu đã phân tích thống kê theo chuỗi thời gian để biết được tình trạng lớp phủ bề mặt trước lũ (giá trị pixel trung bình trong các ảnh trước lũ) và sự khác biệt được tạo ra khi có sự hiện diện của nước lũ (giá trị pixel tối thiểu và tối đa trong các ảnh bao gồm các ảnh trước lũ và trong lúc lũ). Nghiên cứu cũng đưa ra được ngưỡng cho hai chỉ số để thành lập được bản đồ lũ lụt.

Nghiên cứu này thể hiện những ưu điểm như: không phụ thuộc vào người dùng, cho phép có thể dễ dàng tự động thành lập bản đồ lũ một cách nhanh chóng. Việc sử dụng chuỗi ảnh đa thời gian khẳng định thêm về tính chính xác của hình ảnh trước lũ do đó cho phép tách lũ chính xác hơn. Ngoài ra, phương pháp còn có thể nhận diện được những vùng ngập nước dưới thảm thực vật thấp.

So sánh với kết quả điều tra thực địa khẳng định tính chính xác của phương pháp cho vùng được nghiên cứu. $\bigcirc$

\section{Lời cảm ơn}

Nghiên cứu này được hỗ trợ bởi Đề tài "Nghiên cứu xây dựng một số mô hình ứng dụng chuẩn hóa phục vụ thúc đẩy khai thác và nâng cao hiệu quả sử dụng dữ liệu vệ tinh LOTUSat", mã số VT-UD.12/17-20, thuộc chương trình Khoa học và Công nghệ vũ trụ.

\section{Tài liệu tham khảo}

[1]. Hankin, B., et al., Mapping space for water: screening for urban flash flooding. Journal of Flood Risk Management, 2008. 1(1): p. 13-22.

[2]. Wu, H., et al., Evaluation of global flood detection using satellite-based rainfall and a hydrologic model. Journal of Hydrometeorology, 2012. 13(4): p. 1268-1284.

[3]. De Groeve, T., Z. Kugler, and G.R. Brakenridge, Near real time flood alerting for the global disaster alert and coordination system. Proceedings ISCRAM2007, 2006: p. 3339.

[4]. Matgen, P., et al., Towards an automated SAR-based flood monitoring system: Lessons learned from two case studies. Physics and Chemistry of the Earth, Parts A/B/C, 2011. 36(78): p. 241-252.

[5]. Mason, D.C., et al., Improving the TanDEM-X Digital Elevation Model for flood modelling using flood extents from Synthetic Aperture Radar images. Remote sensing of environment, 2016. 173: p. 15-28.

[6]. Quang, N.H., et al., Synthetic aperture radar and optical remote sensing image fusion for flood monitoring in the Vietnam lower Mekong basin: a prototype application for the Vietnam Open Data Cube. European Journal of Remote Sensing, 2019. 52(1): p. 599-612.

[7]. Quang, N.H., et al., Hydrological/Hydraulic Modeling-Based Thresholding of Multi SAR Remote Sensing Data for Flood Monitoring in Regions of the Vietnamese Lower Mekong River Basin. Water, 2020. 12(1): p. 71.

[8]. Rahman, M.R. and P.K. Thakur, Detecting, mapping and analysing offlood water 
propagation using synthetic aperture radar (SAR) satellite data and GIS: A case study from the Kendrapara District of Orissa State of India. The Egyptian Journal of Remote Sensing and Space Science, 2018. 21: p. S37-S41.

[9]. Schlaffer, S., et al., Flood detection from multi-temporal SAR data using harmonic analysis and change detection. International Journal of Applied Earth Observation and Geoinformation, 2015. 38: p. 15-24.

[10]. Giustarini, L., et al., Accounting for image uncertainty in SAR-based flood mapping. International Journal of Applied Earth Observation and Geoinformation, 2015. 34: p. 70-77.

[11]. Kuenzer, C., et al., Flood mapping and flood dynamics of the Mekong Delta: ENVISATASAR-WSM based time series analyses. Remote Sensing, 2013. 5(2): p. 687-715.

[12]. Long, N.T. and B.D. Trong. Flood monitoring of Mekong River delta, Vietnam using ERS SAR data. in Proceedings of the 22nd
Asian Conference on Remote Sensing, Singapore. 2001.

[13]. Sakamoto, T., et al., Detecting temporal changes in the extent of annual flooding within the Cambodia and the Vietnamese Mekong Delta from MODIS time-series imagery. Remote sensing of environment, 2007. 109(3): p. 295313.

[14]. Cian, F., M. Marconcini, and P. Ceccato, Normalized Difference Flood Index for rapid flood mapping: Taking advantage of EO big data. Remote Sensing of Environment, 2018. 209: p. 712-730.

[15]. Long, S., T.E. Fatoyinbo, and F. Policelli, Flood extent mapping for Namibia using change detection and thresholding with SAR. Environmental Research Letters, 2014. 9(3): p. 035002.

[16]. Website, https://thanhnien.vn/thoisu/muc-nuoc-lu-nam-nay-cao-hon-nam-2017984571.html. $\bigcirc$

\section{Summary}

\section{Rapidly Flood Inundation Mapping Using Normalized Difference Flood Index (NDFI) and Normalized Difference Flood in short Vegetation Index (NDFVI) Taking Advantages of the Vietnam Data Cube system}

Le Thi Thu Hang, Vu Anh Tuan, Nguyen Hong Quang

Vietnam National Space Center, Vietnam Academy of Science and Technology

Pham Minh Hai, Vietnam Institute of Geodesy and Cartography

Timely and accurate flood extent mapping is crucial for flood management and responses in order to mitigate flood consequences, especially in the context of climate change. This study applied Normalized Difference Flood Index (NDFI) and Normalized Difference Flood in short Vegetation Index (NDFVI) to map the flood inundation rapidly using time-series Synthetic Aperture Radar (SAR) data, Sentinel-1. The flood maps were generated based on these two indexes calculated for pre and during flood images and the low-vegetation inundated areas classified and added to the flood maps. The Sentinel-1 images are considered suitable and necessary as they are an open data source and the high rate of revisit time (12 days). However, this approach could be applied for other C-band SAR data as well. The flood season in 2018 in Dong Thap province is chosen for the case study with 143 field survey points for accuracy assessment. Our results prove that the applied methods were highly accurate and productive. As the Sentinel-1 data were collected for the entire Vietnam and stored in the Vietnam Data Cube of Vietnam National Space Center, this method of rapid flood mapping is a potential and enable tool applying for the entire Vietnam area. $\bigcirc$ 